\title{
From energetic cobalt pentazolate to cobalt@nitrogen-doped carbons as efficient electrocatalysts for oxygen reduction
}

\author{
Binshen Wang ${ }^{1,2 \dagger}$, Yousong $\mathrm{Liu}^{2 \dagger}$, Mucong Deng ${ }^{2}$, Jin $\mathrm{Luo}^{2}$, Guangcheng Yang ${ }^{2}$, Shiguo Zhang ${ }^{3}$, \\ Jiaheng Zhang ${ }^{1 *}$ and Qinghua Zhang ${ }^{2 *}$
}

\begin{abstract}
Cyclopentazolate anions $\left(\right.$ cyclo- $\left._{5}{ }_{5}^{-}\right)$have been receiving ever-increasing attention as component of energetic explosives since recent fulfilment of the first stable sample in solid phase and ambient conditions. Herein, we present a new strategy to utilize deflagration reactions of cobalt pentazolate in combination with explosive poly(ionic liquid) (EPIL) for the preparation of $\mathrm{Co@N-doped} \mathrm{carbon} \mathrm{materials} \mathrm{with}$ homogeneously distributed cobalt nanoparticle encapsulated by the layers of $\mathrm{N}$-doped carbon sheets. The resultant $5 \% \operatorname{Co}\left(\mathrm{N}_{5}\right)_{2}$-EPIL-900 exhibits high electrocatalytic activities, excellent stability and tolerance to $\mathrm{CH}_{3} \mathrm{OH}$ towards oxygen reduction reaction (ORR). Moreover, the present approach provides a novel routine for preparation of functional materials from energetic and newly-emerging cyclo- $\mathrm{N}_{5}{ }^{-}$-derived compounds.
\end{abstract}

Keywords: pentazole, ionic liquids, carbon materials, deflagration, oxygen reduction reaction

\section{INTRODUCTION}

Polynitrogen compounds have received great attention due to their potential applications in the field of highenergy-density materials (HEDMs). Among the developed polynitrogen compounds, cyclopentazolate anion (cyclo- $\mathrm{N}_{5}^{-}$) represents an important member of all-nitrogen species due to its unique aromatic structure that five nitrogen atoms enter a highly symmetric ring. The cyclo- $\mathrm{N}_{5}{ }^{-}$-derived compounds can release a large amount of energy during the decomposition of $\mathrm{N}-\mathrm{N}$ and $\mathrm{N}=\mathrm{N}$ bonds into $\mathrm{N}_{2}$. Since the successful stabilization of cyclo-
$\mathrm{N}_{5}{ }^{-}$species in condensed phases was realized at ambient conditions by $\mathrm{Lu}$ et al. in 2017 [1,2], the cyclo- $\mathrm{N}_{5}{ }^{-}$ chemistry has attracted worldwide interest because of its potential energetic military applications as high explosives or propellants [3-12]. Despite the tremendous contributions to the cyclo- $\mathrm{N}_{5}{ }^{-}$chemistry, present studies mainly focus on synthesis and properties of new cyclo- $\mathrm{N}_{5}{ }^{-}$ compounds, and the exploration of their potential applications is somewhat rare.

As is well-known that elevated temperature can trigger the explosion of energetic compounds, releasing a large amount of heat and gas in an extremely short time. The deflagration synthesis, i.e., by virtue of thermal explosion of energetic compounds, has provided a platform strategy for the preparation of promising functional materials. In recent years, various functional materials including graphene quantum dots [13], $\mathrm{TiO}_{2}$ nanosheets [14], hollow carbon nanoparticles [15] and $\mathrm{Ni} / \mathrm{La}_{2} \mathrm{O}_{2} \mathrm{CO}_{3}$ [16] have been prepared through the deflagration synthesis. Considering the extremely high detonation velocity and pressure probably produced in thermal explosion process, the metal-containing cyclo- $\mathrm{N}_{5}{ }^{-}$compounds have great potential as novel precursors (i.e., metal and nitrogen sources) for deflagration synthesis of metal modified nitrogen-doped functional materials. Moreover, we recently designed and synthesized a series of explosive poly(ionic liquid)s (EPILs) materials, whose detonation performances were comparable to that of 2,4,6-trinitrotoluene (TNT) [17]. Since Yuan and Antonietti et al. [18] firstly reported the preparation of graphitic mesoporous car-

\footnotetext{
${ }^{1}$ School of Materials Science and Engineering, Harbin Institute of Technology, Shenzhen 518055, China

${ }^{2}$ Research Center of Energetic Material Genome Science, Institute of Chemical Materials, China Academy of Engineering Physics (CAEP), Mianyang 621900, China

${ }^{3}$ College of Materials Science and Engineering, Hunan University, Changsha 410082, China

$\dagger$ These authors contributed equally to this study.

* Corresponding authors (emails: zhangjiaheng@hit.edu.cn (Zhang J); qinghuazhang@caep.cn (Zhang Q))
} 
bons via the carbonization of poly(ionic liquid)s (PILs), a variety of PILs with different structures have been intensely investigated as task-specific precursors for functional carbon materials $[19,20]$. N-doped carbons derived from PILs have demonstrated their potential applications in different fields, including $\mathrm{CO}_{2}$ capture [21], dye removal [22], catalysis [23], electrodes for lithium-ion batteries [24], and supercapacitors [25]. In this context, by virtue of integrating multiple advantages of metal cyclo- $\mathrm{N}_{5}^{-}$salts (e.g., nitrogen-rich, highly energetic, and metal-containing) and EPILs (e.g., explosive ionic polymers, nitrogen-containing carbon precursors), functional metal@nitrogen-doped carbon materials are expected to be prepared via the deflagration method of metal cyclo$\mathrm{N}_{5}{ }^{-}$salts and EPILs for the specific electrocatalytic applications.

Herein, we report the use of novel deflagration reactions of cobalt pentazolate and EPIL to synthesize Co@Ndoped carbon materials with homogeneously distributed cobalt nanoparticles encapsulated by $\mathrm{N}$-doped carbon nanosheet layers. In the deflagration process, cobalt pentazolate plays multiple roles including $\mathrm{Co}$ and $\mathrm{N}$ sources and energy resource for thermal explosion, while EPIL serves as carbon precursor, nitrogen source and the energy material for thermal explosion. The electrocatalytic activities of Co@N-doped carbon materials were particularly studied for oxygen reduction reaction (ORR), which is one of the most fundamental and important reactions in fuel cells and metal-air batteries [26-30].

\section{EXPERIMENTAL SECTION}

\section{Synthesis of $W \% \mathrm{Co}\left(\mathrm{N}_{5}\right)_{2}$-EPIL-X}

$\mathrm{Co}\left(\mathrm{N}_{5}\right)_{2}\left(\mathrm{H}_{2} \mathrm{O}\right)_{4} \cdot 4 \mathrm{H}_{2} \mathrm{O}$ was prepared according to the literature [2,5]. Poly(1H-3-vinylimidazolium nitrate) as EPIL $(1.00 \mathrm{~g})$ was dissolved into $15 \mathrm{~mL}$ of deionized water. Subsequently, the as-prepared $\mathrm{Co}\left(\mathrm{N}_{5}\right)_{2}\left(\mathrm{H}_{2} \mathrm{O}\right)_{4} \cdot 4 \mathrm{H}_{2} \mathrm{O}$ $(0.05 \mathrm{~g})$ was added into the solution. After being stirred for $1 \mathrm{~h}$ at room temperature, the solvent was removed in air. Then the obtained mixture was heated to $600^{\circ} \mathrm{C}$ at a heating rate of $10^{\circ} \mathrm{C} \mathrm{min}^{-1}$ under nitrogen atmosphere, and subsequently heated up to 800,900 or $1000^{\circ} \mathrm{C}$ at a heating rate of $2^{\circ} \mathrm{C} \mathrm{min}^{-1}$ and maintained at the temperature for $2 \mathrm{~h}$. Afterward, the temperature of the oven was reduced to $600^{\circ} \mathrm{C}\left(2^{\circ} \mathrm{C} \mathrm{min}{ }^{-1}\right)$, and then cooled down to room temperature. A black powder was obtained and denoted as $5 \% \mathrm{Co}\left(\mathrm{N}_{5}\right)_{2}$-EPIL-800, $5 \% \mathrm{Co}\left(\mathrm{N}_{5}\right)_{2}$-EPIL-900, $5 \% \mathrm{Co}\left(\mathrm{N}_{5}\right)_{2}$-EPIL-1000, respectively. The preparation procedures of $2 \% \mathrm{Co}\left(\mathrm{N}_{5}\right)_{2}$-EPIL-900 and $8 \% \mathrm{Co}\left(\mathrm{N}_{5}\right)_{2}$ EPIL-900 were the same as that of $5 \% \operatorname{Co}\left(\mathrm{N}_{5}\right)_{2}$-EPIL-900, except that 0.02 or $0.08 \mathrm{~g} \mathrm{Co}\left(\mathrm{N}_{5}\right)_{2}\left(\mathrm{H}_{2} \mathrm{O}\right)_{4} \cdot 4 \mathrm{H}_{2} \mathrm{O}$ was used as precursors.

\section{Synthesis of EPIL- $X$}

Poly $(1 H$-3-vinylimidazolium nitrate $)(1.00 \mathrm{~g})$ was heated to $600^{\circ} \mathrm{C}$ at a heating rate of $10^{\circ} \mathrm{C} \mathrm{min}{ }^{-1}$ under nitrogen atmosphere, and subsequently heated up to $700,800,900$ or $1000^{\circ} \mathrm{C}$ respectively at a heating rate of $2^{\circ} \mathrm{C} \mathrm{min}^{-1}$ and maintained at the temperature for $2 \mathrm{~h}$. Afterward, the temperature of the oven was reduced to $600^{\circ} \mathrm{C}\left(2^{\circ} \mathrm{C} \mathrm{min}^{-1}\right)$, and then cooled down to room temperature. A black powder was finally obtained and denoted as EPIL-700, EPIL-800, EPIL-900, or EPIL-1000, respectively.

\section{Characterizations}

Scanning electron microscopy (SEM) was operated on a Hitachi S-4800 microscope. Transmission electron microscopy (TEM) was performed on a FEI Tecnai G2 F30 microscope working at $300 \mathrm{kV}$. X-ray diffraction (XRD) analyses were collected on Bruker D8 ADVANCE with $\mathrm{Cu}-\mathrm{Ka}$ radiation, $\lambda=1.5418 \AA$. The Raman spectra were recorded by a Renishaw Raman RE01 scope using a $785 \mathrm{~nm}$ infrared laser. The specific surface area and pore information were measured on a Micromeritics ASAP 2020 Surface Area and Porosity Analyzer by nitrogen adsorption-desorption. X-ray photoelectron spectroscopy (XPS) analyses were recorded on ESCALAB 250 XPS Xray Electron Spectrometer (American Thermo Electron Corporation). Inductively coupled plasma atomic emission spectroscopy (ICP-AES) was performed on Shimadzu ICPS-8100.

\section{Electrochemical measurements}

The ORR activities were measured on a $\mathrm{CHI} 750 \mathrm{C}(\mathrm{CH}$ Instrument Inc., Austin, TX, USA) which was equipped with a three-electrode system in $\mathrm{O}_{2}$-saturated $0.1 \mathrm{~mol} \mathrm{~L}^{-1}$ $\mathrm{KOH}(\mathrm{pH} 13)$ solution. Glassy carbon electrode (GC, $5 \mathrm{~mm}$ in diameter, $\sim 0.1963 \mathrm{~cm}^{2}$ ) coated with the as-prepared catalyst ink was used as the working electrode. An $\mathrm{Ag} / \mathrm{AgCl}$ electrode was used as the reference electrode, and a platinum plate was used as the counter electrode. The working electrode was produced as follows: $10 \mathrm{mg}$ of the as-prepared catalyst or $20 \mathrm{wt} \% \mathrm{Pt} / \mathrm{C}$ was added into a mixture containing $250 \mu \mathrm{L}$ water, $750 \mu \mathrm{L}$ ethanol, and $40 \mu \mathrm{L}$ Nafion solution. The solution was ultrasonicated for $2 \mathrm{~h}$ to obtain a homogeneous suspension ink. Then $10 \mu \mathrm{L}$ of the catalyst ink was pipetted onto the surface of the polished GC electrode to form a thin catalyst film on the GC electrode. After drying in ambient air, the working electrode was placed on the rotating pole for 
experiments. All of the potentials were calibrated to the reversible hydrogen electrode (RHE) based on the equation: $E_{v s . \mathrm{RHE}}=E_{v s . \mathrm{Ag} / \mathrm{AgCl}}+0.209+0.059 \mathrm{pH}$, and the current density $(J)$ was normalized to the geometrical area of the working electrode.

For the ORR at a rotating disk electrode (RDE), the electron transfer numbers $(n)$ could be calculated with Koutecky-Levich equations

$\frac{1}{J}=\frac{1}{J_{\mathrm{L}}}+\frac{1}{J_{\mathrm{K}}}=\frac{1}{B \omega^{1 / 2}}+\frac{1}{J_{\mathrm{K}}}$,

$B=0.62 n F C_{0}\left(D_{0}\right)^{2 / 3} v^{-1 / 6}$,

where $J$ was the measured current density. $J_{\mathrm{K}}$ and $J_{\mathrm{L}}$ were the kinetic and diffusion-limiting current densities, respectively. $\omega$ was the angular velocity of the disk $(\omega=$ $2 \pi N, N$ was the linear rotation speed). $F$ was the Faraday constant $\left(F=96,485 \mathrm{C} \mathrm{mol}^{-1}\right)$. $C_{0}$ was the bulk concentration of $\mathrm{O}_{2}\left(1.2 \times 10^{-6} \mathrm{~mol} \mathrm{~cm}^{-3}\right) . D_{0}$ was the diffusion coefficient of $\mathrm{O}_{2}$ in $0.1 \mathrm{~mol} \mathrm{~L}^{-1} \mathrm{KOH}$ electrolyte $\left(1.9 \times 10^{-5} \mathrm{~cm}^{2} \mathrm{~s}^{-1}\right) . v$ was the kinematics viscosity for electrolyte $\left(0.01 \mathrm{~cm}^{2} \mathrm{~s}^{-1}\right)$.

Moreover, methanol tolerance tests were performed by chronoamperometric cures with addition of $5 \mathrm{vol} \%$ methanol at around $300 \mathrm{~s}$ during the ORR.

\section{RESULTS AND DISCUSSION}

The deflagration preparation procedure of Co@N-doped carbons was shown in Scheme 1. First, the precursor solution was obtained by mixing cobalt pentazolate and EPIL, i.e., poly(1H-3-vinylimidazolium nitrate). Then, the dried precursor was heated up to $900^{\circ} \mathrm{C}$ under continuous $\mathrm{N}_{2}$ flow. The elevated temperature triggered the thermal explosion of cobalt pentazolate and EPIL. The decomposition of cobalt pentazolate produced the $\mathrm{N}$ radicals and Co nanoclusters, which were doped into carbon substance in-situ produced from the incomplete deflagration and carbonization of EPIL, affording the resultant Co@N-doped carbon materials, i.e., $5 \% \mathrm{Co}\left(\mathrm{N}_{5}\right)_{2}$-EPIL900. In order to study the pyrolysis behavior of the pre- cursor mixture of cobalt pentazolate and EPIL, differential thermal analysis (DTA) was tested. As shown in Fig. S1, two remarkable exothermic peaks were observed at 183.2 and $224.3^{\circ} \mathrm{C}$, which were related to the detonation temperatures of cobalt pentazolate and EPIL, respectively. It clearly demonstrated that the mixture of cobalt pentazolate and EPIL underwent two deflagration reactions in this heating process. As comparison, $\mathrm{N}$ doped carbons were produced by heating the EPIL in the absence of cobalt pentazolate at $700,800,900,1000^{\circ} \mathrm{C}$, respectively (denoted as EPIL- $X, X$ means the temperature). The morphologies and microstructures of the obtained carbonaceous materials were characterized by SEM, TEM, XRD, Raman spectra, nitrogen adsorption/ desorption measurements, XPS and ICP-AES, respectively.

SEM images showed that the morphology of EPIL-900 was primarily stacked with sheet-like structures, and cobalt particles were successfully supported on the $\mathrm{N}$-doped carbon sheet of $5 \% \mathrm{Co}\left(\mathrm{N}_{5}\right)_{2}$-EPIL-900 (Fig. S2). As depicted in TEM images of $5 \% \mathrm{Co}\left(\mathrm{N}_{5}\right)_{2}$-EPIL-900 in Fig. 1a-c, the size of cobalt nanoparticles ranged from about 50 to $100 \mathrm{~nm}$. Abundant graphitic carbon structures were observed due to the catalytic graphitization behavior of Co nanoparticles [31]. Each cobalt nanoparticle was encased by the layers of $\mathrm{N}$-doped carbon sheets forming the core-shell nanostructures (Fig. 1d). Lattice fringes of core Co (111) plane with a $d$-spacing of $0.206 \mathrm{~nm}$ and a shell with typical graphene layers with an interlayer spacing of $0.340 \mathrm{~nm}$ were observed, as shown in Fig. 1e. Recent studies demonstrated that Co nanoparticles in core-shell structure could promote the effective adsorption and activation of oxygen molecules, and then accelerate the reaction kinetics for ORR [32]. Carbon layers were conducive to preventing agglomeration of metal over time, and hence improving their stability, leading to the enhanced catalytic ORR performances. STEM-EDX elemental mappings in Fig. 1f-h showed that carbon and nitrogen elements were uniformly distributed

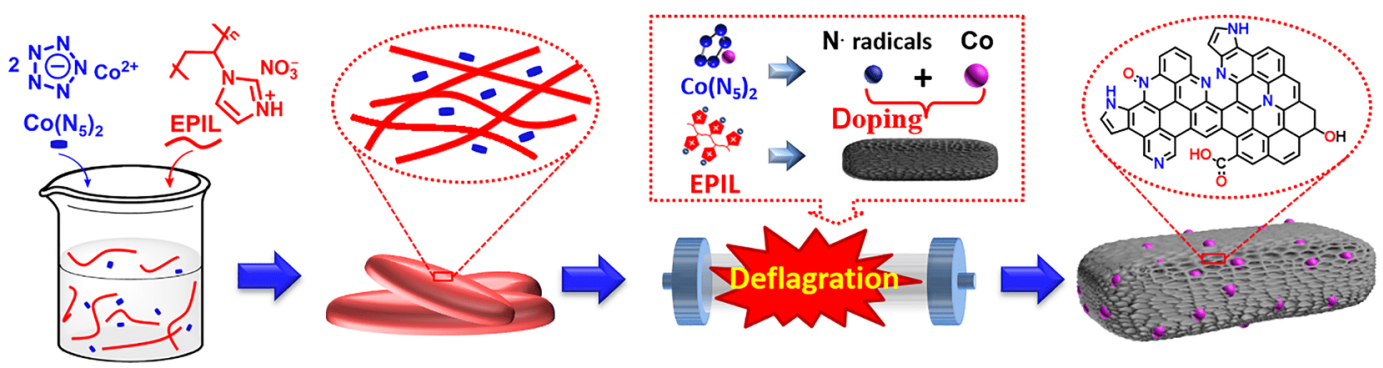

Scheme 1 Synthesis route for cobalt pentazolate and EPIL to $5 \% \mathrm{Co}\left(\mathrm{N}_{5}\right)_{2}$-EPIL-900. 

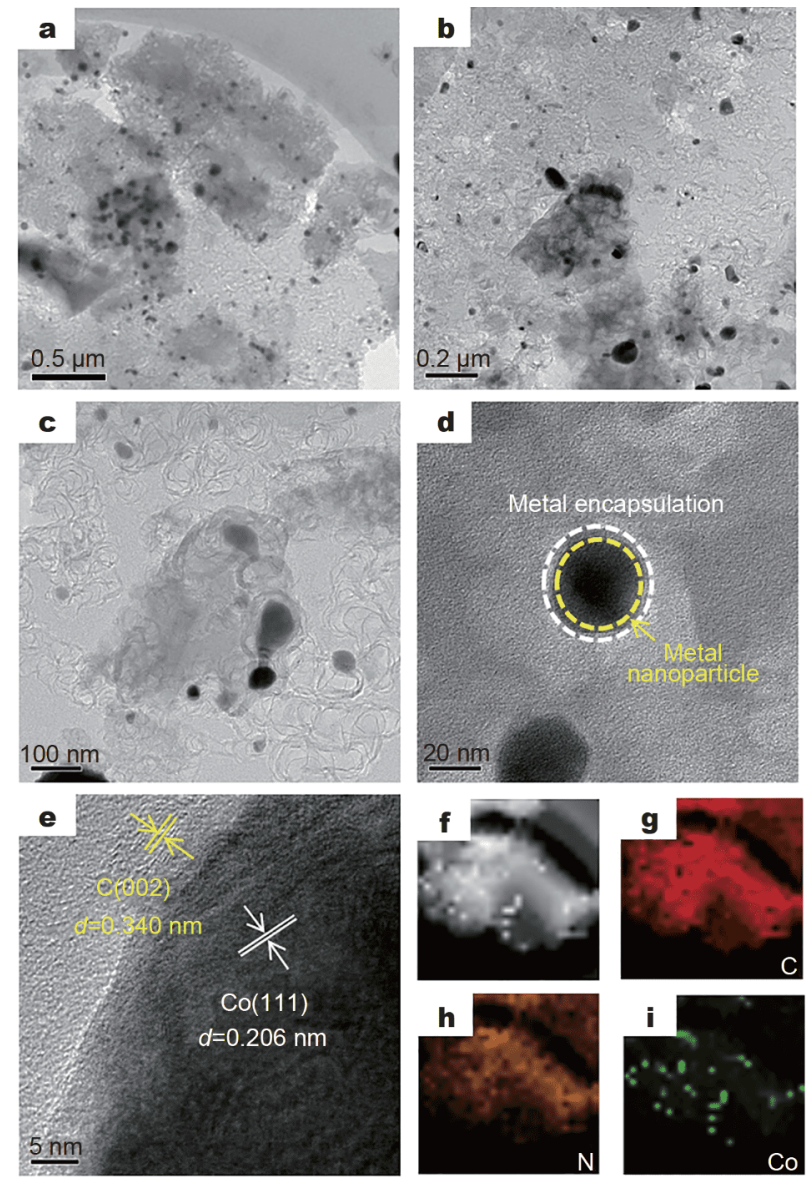

Figure 1 (a-e) TEM images, (f) STEM image, (g) carbon, (h) nitrogen, and (i) cobalt elemental mapping of $5 \% \mathrm{Co}\left(\mathrm{N}_{5}\right)_{2}$-EPIL- 900 .

in $5 \% \mathrm{Co}\left(\mathrm{N}_{5}\right)_{2}$-EPIL-900 sample. Fig. 1i demonstrated the homogeneous distribution of cobalt into the carbon substrate in the form of granular particles, which was partly attributed to a violent explosion of cobalt pentazolate during the deflagration process. Fig. S3 exhibited the morphologies of other $W \% \mathrm{Co}\left(\mathrm{N}_{5}\right)_{2}$-EPIL- $X$ samples with homogeneously distributed cobalt nanoparticles. As shown in Figs S4 and S5, the samples of EPIL- $X$ series had sheet-like nanostructures with an average size of $\sim 2 \mu \mathrm{m}$ and thickness of $\sim 50 \mathrm{~nm}$, implying that EPIL served as the template in the deflagration process.

XRD patterns of $W \% \mathrm{Co}\left(\mathrm{N}_{5}\right)_{2}$-EPIL- $X$ and EPIL- $X$ series samples exhibited two peaks at $\sim 24^{\circ}$ and $\sim 44^{\circ}$, which corresponded to the (002) and (101) planes of carbon, respectively (JCPDF\#41-1487) (Fig. 2a and Fig. S6). Compared with EPIL-900, the additional XRD peaks of $5 \% \mathrm{Co}\left(\mathrm{N}_{5}\right)_{2}$-EPIL-900 at $44.5^{\circ}, 51.0^{\circ}$, and $75.8^{\circ}$ were assignable to the (111), (200) and (220) planes of metallic Co, respectively (JCPDF\#15-0806). In the Raman spectra of $W \% \mathrm{Co}\left(\mathrm{N}_{5}\right)_{2}$-EPIL- $X$ and EPIL- $X$ samples, two peaks were located at $\sim 1350$ and $\sim 1580 \mathrm{~cm}^{-1}$, corresponding to the D-band (disordered graphite structure) and G-band ( $\mathrm{sp}^{2}$-hybridized carbon) of carbon materials, respectively (Fig. $2 \mathrm{~b}$ and Fig. S7). Additionally, $5 \% \mathrm{Co}\left(\mathrm{N}_{5}\right)_{2}$-EPIL-900 exhibited a distinct peak at $\sim 676 \mathrm{~cm}^{-1}$ owing to the doped Co-species [33]. The $I_{\mathrm{D}} / I_{\mathrm{G}}$ value of EPIL-900 was 0.86 , while it was improved to 0.95 in the $5 \% \mathrm{Co}\left(\mathrm{N}_{5}\right)_{2}$-EPIL-900 sample probably due to the increased defects caused by the doped Co-species. To gain insights into the porosity of $W \% \mathrm{Co}\left(\mathrm{N}_{5}\right)_{2}$-EPIL- $X$ and EPIL- $X$ series samples, nitrogen adsorption/desorption measurements were performed. The isotherm of $5 \% \mathrm{Co}\left(\mathrm{N}_{5}\right)_{2}$-EPIL-900 resembled type IV with an obvious hysteresis loop, demonstrating the existence of hierarchically porous structures (Fig. 2c and Fig. S8). The isotherm of EPIL-900 presented type I characteristics with a steep increase at ultralow relative pressure $\left(P / P_{0}<0.05\right)$, indicating the presence of an abundance of microporous structures (Fig. $2 \mathrm{c}$ and Fig. S9). The Brunner-Emmet-Teller (BET) specific surface area of $5 \% \mathrm{Co}\left(\mathrm{N}_{5}\right)_{2}$-EPIL-900 was measured as $181 \mathrm{~m}^{2} \mathrm{~g}^{-1}$ (Table S1). As shown in Fig. 2d and Fig. S10, the pore-size distribution (PSD) analysis showed the co-existence of micropore and mesopore in $5 \% \mathrm{Co}\left(\mathrm{N}_{5}\right)_{2}$-EPIL-900 and other $W \% \mathrm{Co}\left(\mathrm{N}_{5}\right)_{2}$-EPIL- $X$ samples. In contrast, the pore sizes of EPIL- $X$ series samples were mostly smaller than $2 \mathrm{~nm}$.

The surface chemical compositions and states of the samples were further characterized by XPS. The XPS survey spectra shown in Fig. 3a confirmed the presence of $\mathrm{Co}, \mathrm{N}, \mathrm{C}$ and $\mathrm{O}$ in $5 \% \mathrm{Co}\left(\mathrm{N}_{5}\right)_{2}$-EPIL-900. The EPIL-900 and other EPIL- $X$ series samples contained $\mathrm{N}, \mathrm{C}$ and $\mathrm{O}$ species (Fig. S11 and Table S2). The high-resolution C 1s spectra of $W \% \mathrm{Co}\left(\mathrm{N}_{5}\right)_{2}$-EPIL- $X$ and EPIL- $X$ were deconvoluted into four peaks corresponding to the $\mathrm{sp}^{2}$-graphitic carbon $(284.7 \mathrm{eV}), \quad \mathrm{C}-\mathrm{N} \quad(285.6 \mathrm{eV}), \quad \mathrm{C}-\mathrm{O}$ $(287.1 \mathrm{eV})$ and $\mathrm{O}=\mathrm{C}-\mathrm{O}(289.3 \mathrm{eV})$ (Fig. $3 \mathrm{~b}$ and Fig. S12) [34], which exhibited that the carbon was bonded to nitrogen and surrounding oxygen species. The high-resolution $\mathrm{N}$ 1s spectra were curve-fitted into four individual peaks: pyridinic $\mathrm{N}(398.4 \mathrm{eV})$, pyrrolic N/Co $-\mathrm{N}(400.3 \mathrm{eV})$, graphitic $\mathrm{N}(401.2 \mathrm{eV})$ and oxidized $\mathrm{N}$ $(403.6 \mathrm{eV})$ (Fig. $3 \mathrm{c}$ and Fig. S13) [35]. The quantitative analyses of $5 \% \mathrm{Co}\left(\mathrm{N}_{5}\right)_{2}$-EPIL-900 sample indicated that the amount of pyridinic $\mathrm{N}(26.0 \%)$, pyrrolic $\mathrm{N} / \mathrm{Co}^{-} \mathrm{N}$ (22.1\%), and graphitic $\mathrm{N}(34.6 \%)$ were significantly more than that of oxidized $\mathrm{N}(17.3 \%)$. It has been reported that the first three $\mathrm{N}$ species play crucial roles in the ORR process [31]. The high-resolution Co $2 p$ spectrum of $5 \%$ $\mathrm{Co}\left(\mathrm{N}_{5}\right)_{2}$-EPIL-900 and other $W \% \mathrm{Co}\left(\mathrm{N}_{5}\right)_{2}$-EPIL- $X$ sam- 

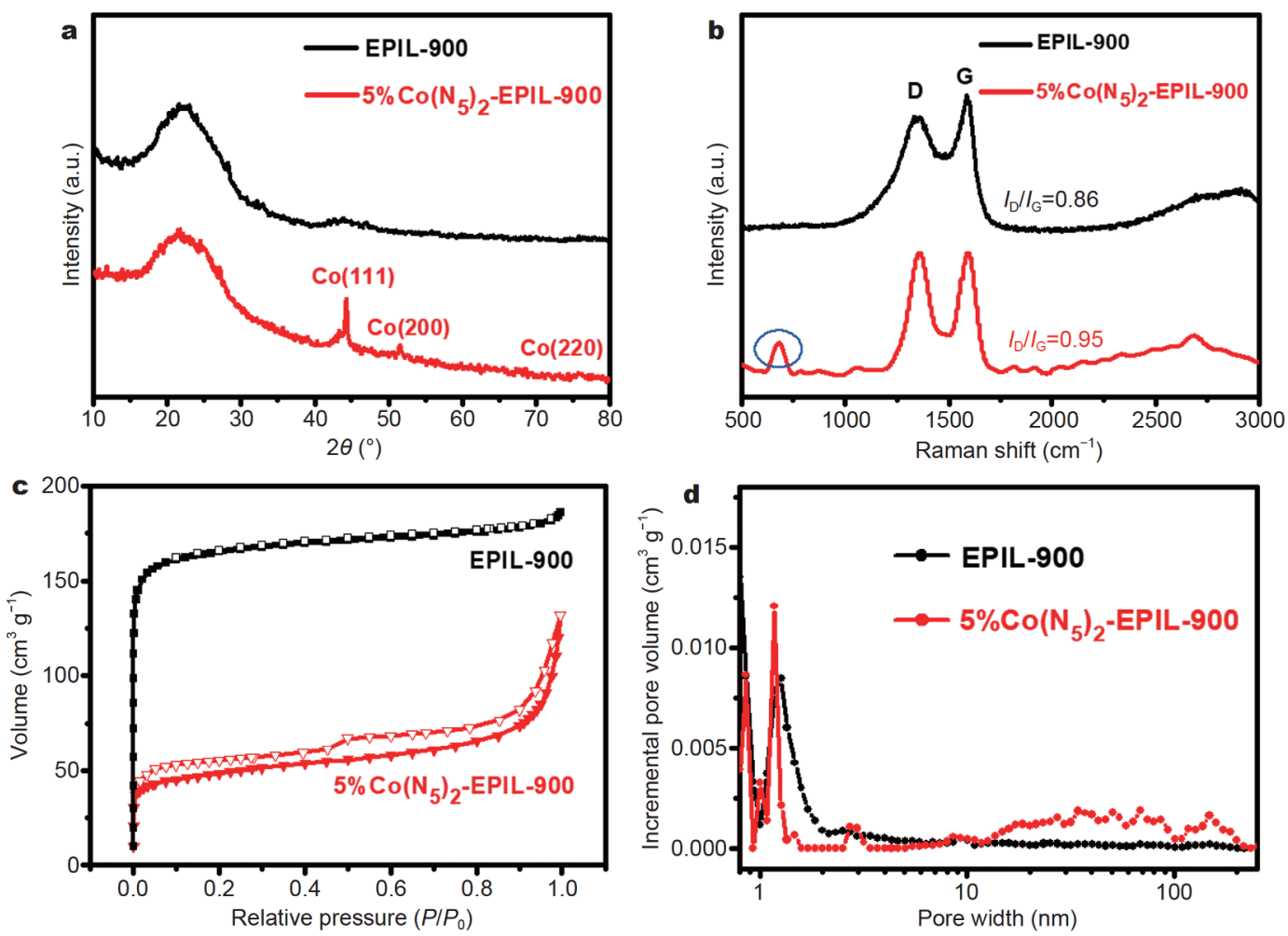

Figure 2 (a) XRD patterns, (b) Raman spectra, (c) $\mathrm{N}_{2}$ adsorption/desorption isotherms at $77 \mathrm{~K}$, amd (d) pore size distribution plots of $5 \% \operatorname{Co}\left(\mathrm{N}_{5}\right)_{2}{ }^{-}$ EPIL-900 and EPIL-900.

ples consisted of Co $2 \mathrm{p}_{1 / 2}$, Co $2 \mathrm{p}_{3 / 2}$ and their corresponding satellites (Fig. 3d and Fig. S14). The Co $2 \mathrm{p}_{3 / 2}$ spectrum was deconvoluted into three sharp peaks at $779.1,780.8$, and $782.4 \mathrm{eV}$, attributed to metallic Co, $\mathrm{Co}_{x} \mathrm{O}_{y}$, and $\mathrm{Co}^{-} \mathrm{N}_{x}$, respectively [36]. It demonstrated the presence of $\mathrm{Co}^{-} \mathrm{N}_{x}$, which had been identified as one of the most efficient active sites for ORR [31]. Futhermore, the bulk composition of Co atoms in $W \% \operatorname{Co}\left(\mathrm{N}_{5}\right)_{2}$-EPIL- $X$ series samples were investigated by ICP-AES and the results were listed in Table S2.

Co-based materials exhibit great application potentials in electrochemical fields because of their extraordinary physicochemical properties [37-41]. The ORR performances of the as-prepared samples were measured in a conventional three-electrode system in $\mathrm{O}_{2}$-saturated $0.1 \mathrm{~mol} \mathrm{~L}^{-1} \mathrm{KOH}$ environment. As shown in Fig. 4a, a well-defined cathodic peak was observed for $5 \% \mathrm{Co}\left(\mathrm{N}_{5}\right)_{2}{ }^{-}$ EPIL-900 at $\sim 0.78 \mathrm{~V}$ in $\mathrm{O}_{2}$-saturated electrolyte while no sharp reduction peak was detected under inert $\mathrm{N}_{2}$-saturated situation, confirming its ORR catalytic activity. Compared with $5 \% \mathrm{Co}\left(\mathrm{N}_{5}\right)_{2}$-EPIL-900, the oxygen reduction peak for EPIL-900 shifted to more negative potential (Fig. S15). Linear sweep voltammograms (LSV) of
$\mathrm{RDE}$ measurements were recorded at a rotating speed of $1600 \mathrm{rpm}$ (Fig. $4 \mathrm{~b}$ and Fig. S16). $5 \% \mathrm{Co}\left(\mathrm{N}_{5}\right)_{2}$-EPIL-900 exhibited a higher half-wave potential of $0.77 \mathrm{~V}$ than that of EPIL-900 $\left(E_{1 / 2}=0.71 \mathrm{~V}\right)$. The onset potentials for the ORR of $5 \% \mathrm{Co}\left(\mathrm{N}_{5}\right)_{2}$-EPIL-900 and EPIL-900 were 0.83 and $0.82 \mathrm{~V}$, respectively. $5 \% \mathrm{Co}\left(\mathrm{N}_{5}\right)_{2}$-EPIL-900 also showed obvious enhancement in limiting current density in comparison with EPIL-900. It revealed that the introduction of cobalt pentazolate as precursor favored the improvement of ORR catalytic activity for the resultant carbon materials. In addition, the ORR performance of $5 \% \mathrm{Co}\left(\mathrm{N}_{5}\right)_{2}$-EPIL-900 was found to be superior to the sample prepared from cobalt nitrate as precursor (Fig. S17), which demonstrated the advantage of energetic cobalt pentazolate over the commonly used cobalt precursor. A comparison between $5 \% \mathrm{Co}\left(\mathrm{N}_{5}\right)_{2}$-EPIL-900 with recently reported cobalt-based catalysts was listed in Table S3. Koutechy-Levich (K-L) analysis was performed to further investigate the ORR kinetics via RDE measurements at various rotating speeds from 400 to $2500 \mathrm{rpm}$ (Fig. 4c). K-L plots $\left(J^{-1}\right.$ vs. $\left.\omega^{-1 / 2}\right)$ were derived from the LSV curves, and all plots showed good linearity (Fig. 4d). The electron transfer number $(n)$ for the ORR 

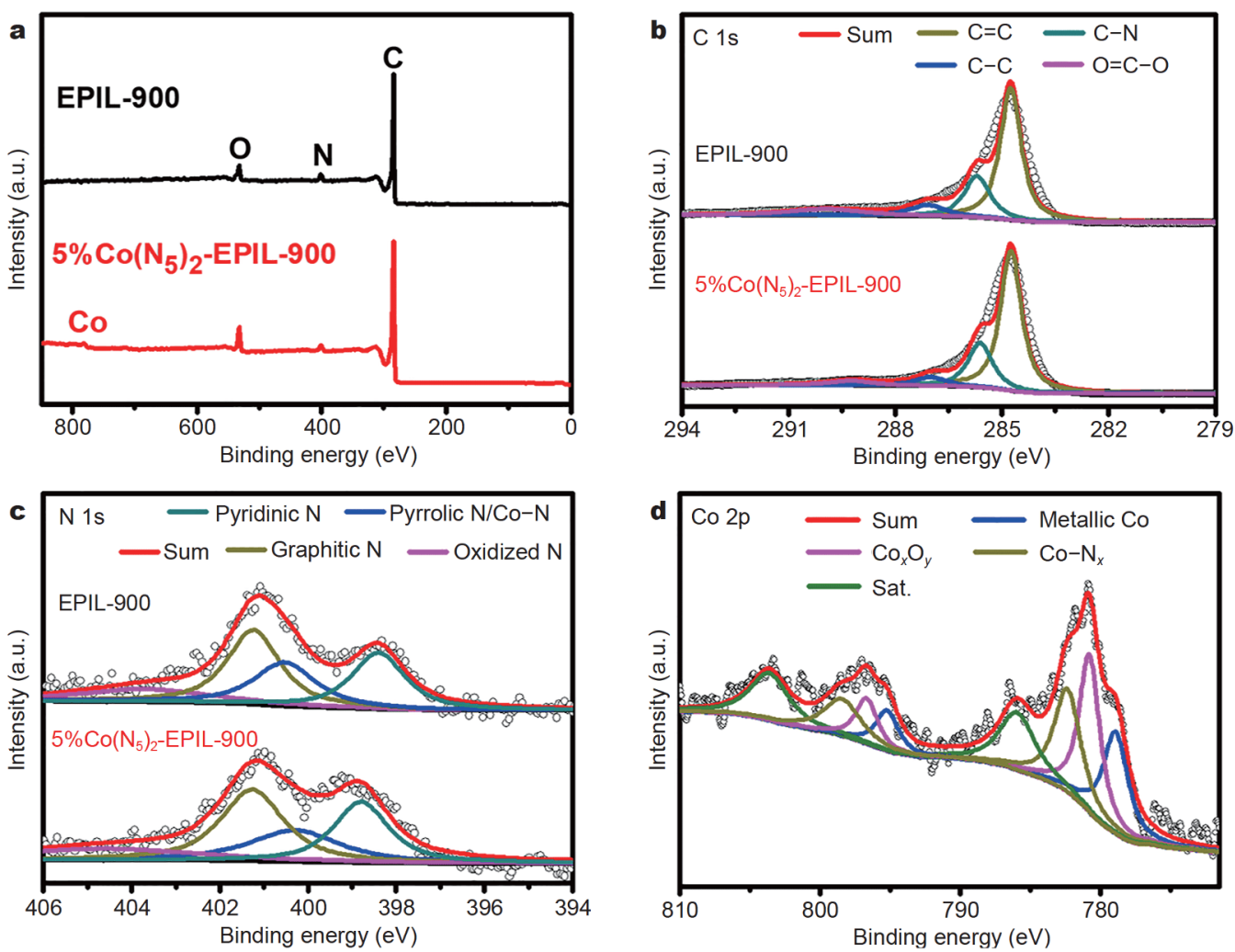

Figure 3 (a) XPS spectra, high resolution XPS (b) C 1s spectra, (c) N 1s spectra of 5\%Co( $\left.\mathrm{N}_{5}\right)_{2}$-EPIL-900 and EPIL-900, and (d) high resolution XPS Co $2 \mathrm{p}$ spectra of $5 \% \mathrm{Co}\left(\mathrm{N}_{5}\right)_{2}$-EPIL-900.
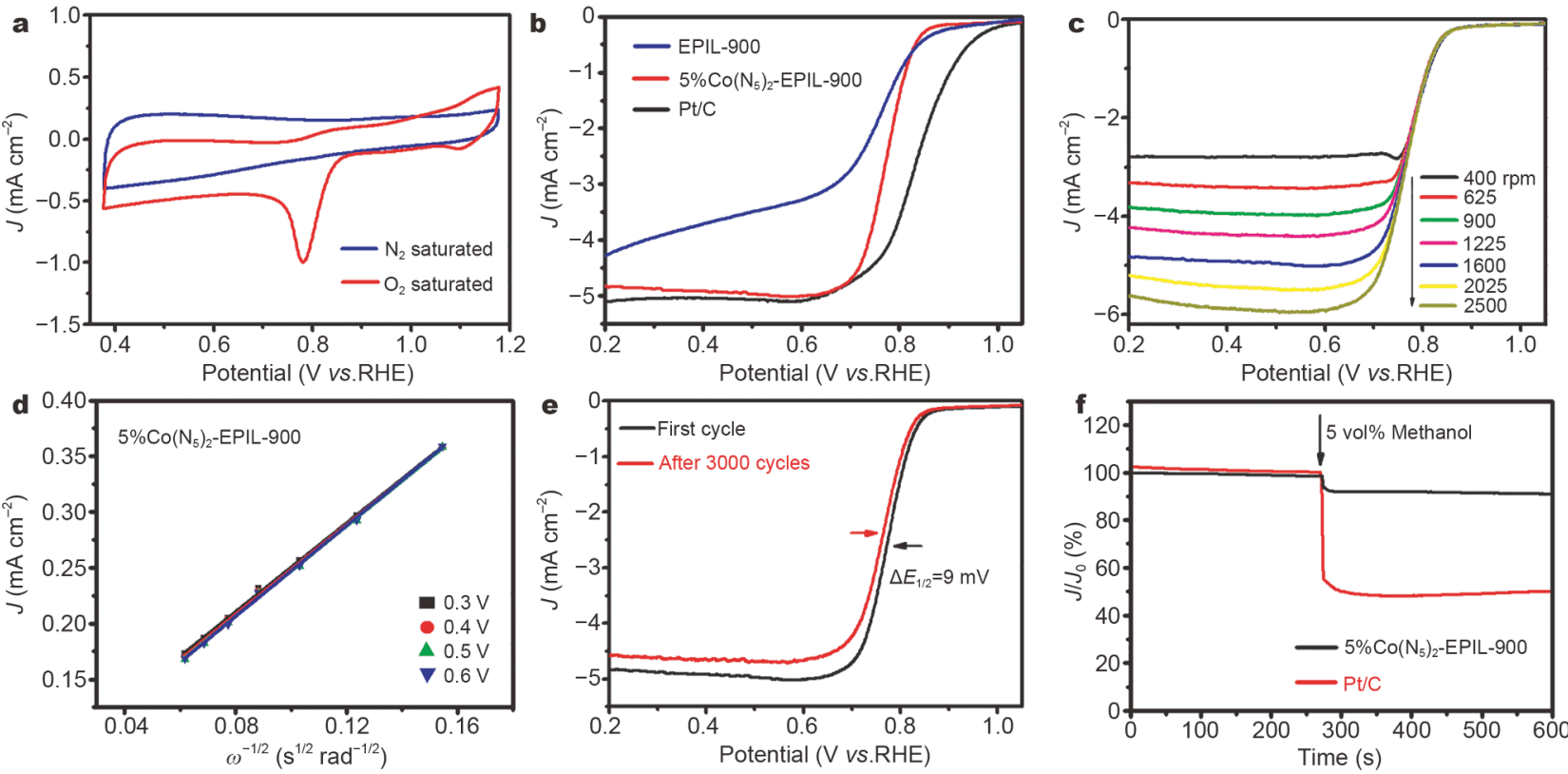

Figure 4 (a) CV curves of $5 \% \mathrm{Co}\left(\mathrm{N}_{5}\right)_{2}$-EPIL-900 in $\mathrm{O}_{2}$ or $\mathrm{N}_{2}$-saturated $0.1 \mathrm{~mol} \mathrm{~L}^{-1} \mathrm{KOH}$ aqueous solution at a sweep rate of $10 \mathrm{mV} \mathrm{s}^{-1}$. (b) LSV curves of studied samples and commercial Pt/C catalyst (20\%, E-TEK) at a scan rate of $10 \mathrm{mV} \mathrm{s}^{-1}$ and a rotating speed of $1600 \mathrm{rpm}$. (c) LSV curves of $5 \% \mathrm{Co}\left(\mathrm{N}_{5}\right)_{2}$-EPIL-900 at different rotating rates. (d) K-L plots at various potentials based on the curves in (c). (e) LSV curves of $5 \% \mathrm{Co}\left(\mathrm{N}_{5}\right)_{2}$-EPIL-900 before and after 3000 cycles. (f) Methanol tolerance curves of 5\%Co(N $\left.\mathrm{N}_{5}\right)_{2}$-EPIL-900 and commercial Pt/C catalyst. 
on $5 \% \operatorname{Co}\left(\mathrm{N}_{5}\right)_{2}$-EPIL-900, determined from the slopes of the K-L plots, was approximately 4.0 , consistent with a four-electron transfer process for the ORR.

In order to test the catalyst's durability, CV measurements of $5 \% \mathrm{Co}\left(\mathrm{N}_{5}\right)_{2}$-EPIL-900 sample was conducted continually at a scan rate of $50 \mathrm{mV} \mathrm{s}^{-1}$ in the $\mathrm{O}_{2}$-saturated $0.1 \mathrm{~mol} \mathrm{~L}^{-1} \mathrm{KOH}$ electrolyte. As shown in Fig. 4e, a negative shift of only $9 \mathrm{mV}$ in the half-wave potential and a decrease of $0.3 \mathrm{~mA} \mathrm{~cm}^{-2}$ in limiting current density were observed after 3000 cycles, demonstrating its good durability. Moreover, the tolerance towards methanol oxidation was also important to evaluate the performance of ORR electrocatalysts. As shown in Fig. 4f, $5 \% \mathrm{Co}\left(\mathrm{N}_{5}\right)_{2}$ EPIL-900 exhibited nearly no fluctuation on ORR current response after addition of $5 \mathrm{vol} \%$ methanol, while the commercial $\mathrm{Pt} / \mathrm{C}$ catalyst under same conditions showed a clear anodic current change related to the methanol oxidization. It indicated an excellent methanol tolerance capability of the synthesized Co@N-doped carbon catalyst.

\section{CONCLUSIONS}

In summary, we demonstrate the novel deflagration synthesis of Co@N-doped carbon materials from nitrogen-rich cobalt pentazolate and EPIL. Benefiting from the violent explosion of two energetic precursors under heat treatment, the resultant carbon material $5 \% \mathrm{Co}\left(\mathrm{N}_{5}\right)_{2}$ EPIL-900 shows unique core-shell nanostructures with uniform distribution of Co nanoparticles encapsulated by graphitized carbon sheets. As an electrocatalyst applied in alkaline electrolyte, $5 \% \mathrm{Co}\left(\mathrm{N}_{5}\right)_{2}$-EPIL-900 exhibited high ORR activities $\left(E_{\text {onset }}=0.83 \mathrm{~V}, E_{1 / 2}=0.77 \mathrm{~V}, J_{\mathrm{K}}=\right.$ $4.83 \mathrm{~mA} \mathrm{~cm}^{-2}$ ) compared to the carbonaceous materials in the absence of cobalt (EPIL-X), good long-term stability and methanol tolerance in contrast to the commercial Pt/C. The outstanding ORR activity and durability of $5 \% \mathrm{Co}\left(\mathrm{N}_{5}\right)_{2}$-EPIL-900 are probably attributed to its unique core-shell structures derived from deflagration reactions. This work provides a promising strategy for preparing high-performance ORR electrocatalysts by virtue of deflagration synthesis method and also opens avenues to explore potential applications for the newly emerging nitrogen-rich cyclo- $\mathrm{N}_{5}^{-}$compounds.

\section{Received 14 March 2019; accepted 14 June 2019;} published online 5 July 2019

1 Zhang C, Sun C, Hu B, et al. Synthesis and characterization of the pentazolate anion cyclo- $\mathrm{N}_{5}{ }^{-}$in $\left(\mathrm{N}_{5}\right)_{6}\left(\mathrm{H}_{3} \mathrm{O}\right)_{3}\left(\mathrm{NH}_{4}\right)_{4} \mathrm{Cl}$. Science, 2017, 355: 374-376

2 Xu Y, Wang Q, Shen C, et al. A series of energetic metal penta- zolate hydrates. Nature, 2017, 549: 78-81

3 Wang $\mathrm{P}, \mathrm{Xu} \mathrm{Y}$, Lin $\mathrm{Q}$, et al. Recent advances in the syntheses and properties of polynitrogen pentazolate anion $c y c l o-\mathrm{N}_{5}^{-}$and its derivatives. Chem Soc Rev, 2018, 47: 7522-7538

4 Sun C, Zhang C, Jiang C, et al. Synthesis of $\mathrm{AgN}_{5}$ and its extended 3D energetic framework. Nat Commun, 2018, 9: 1269-1275

5 Zhang C, Yang C, Hu B, et al. A symmetric $\mathrm{Co}\left(\mathrm{N}_{5}\right)_{2}\left(\mathrm{H}_{2} \mathrm{O}\right)_{4} \cdot 4 \mathrm{H}_{2} \mathrm{O}$ high-nitrogen compound formed by Cobalt(II) cation trapping of a cyclo- $\mathrm{N}_{5}^{-}$anion. Angew Chem Int Ed, 2017, 56: 4512-4514

6 Zhang W, Wang K, Li J, et al. Stabilization of the pentazolate anion in a zeolitic architecture with $\mathrm{Na}_{20} \mathrm{~N}_{60}$ and $\mathrm{Na}_{24} \mathrm{~N}_{60}$ nanocages. Angew Chem Int Ed, 2018, 57: 2592-2595

7 Xu Y, Wang P, Lin Q, et al. A carbon-free inorganic-metal complex consisting of an all-nitrogen pentazole anion, a $\mathrm{Zn}$ (II) cation and $\mathrm{H}_{2} \mathrm{O}$. Dalton Trans, 2017, 46: 14088-14093

8 Wang PC, Xu YG, Wang Q, et al. Self-assembled energetic coordination polymers based on multidentate pentazole cyclo- $\mathrm{N}_{5}{ }^{-}$. Sci China Mater, 2019, 62: 122-129

9 Xu Y, Wang P, Lin Q, et al. Self-assembled energetic 3D metalorganic framework $\left[\mathrm{Na}_{8}\left(\mathrm{~N}_{5}\right)_{8}\left(\mathrm{H}_{2} \mathrm{O}\right)_{3}\right]_{n}$ based on cyclo- $\mathrm{N}_{5}^{-}$. Dalton Trans, 2018, 47: 1398-1401

10 Yang C, Zhang C, Zheng Z, et al. Synthesis and characterization of cyclo-pentazolate salts of $\mathrm{NH}_{4}{ }^{+}, \mathrm{NH}_{3} \mathrm{OH}^{+}, \mathrm{N}_{2} \mathrm{H}_{5}{ }^{+}, \mathrm{C}\left(\mathrm{NH}_{2}\right)_{3}{ }^{+}$, and $\mathrm{N}\left(\mathrm{CH}_{3}\right)_{4}{ }^{+}$. J Am Chem Soc, 2018, 140: 16488-16494

11 Wang $\mathrm{P}$, Lin $\mathrm{Q}, \mathrm{Xu} \mathrm{Y}$, et al. Pentazole anion $c y c l o-\mathrm{N}_{5}{ }^{-}$: a rising star in nitrogen chemistry and energetic materials. Sci China Chem, 2018, 61: 1355-1358

12 Li J, Wang K, Song S, et al. $\left[\mathrm{LiNa}\left(\mathrm{N}_{5}\right)_{2}\left(\mathrm{H}_{2} \mathrm{O}\right)_{4}\right] \mathrm{H}_{2} \mathrm{O}$ : a novel heterometallic cyclo- $\mathrm{N}_{5}{ }^{-}$framework with helical chains. Sci China Mater, 2019, 62: 283-288

13 Liu Y, Gao B, Qiao Z, et al. Gram-scale synthesis of graphene quantum dots from single carbon atoms growth via energetic material deflagration. Chem Mater, 2015, 27: 4319-4327

14 Liu Y, Ouyang S, Guo W, et al. Ultrafast one-step synthesis of N and $\mathrm{Ti}^{3+}$ codoped $\mathrm{TiO}_{2}$ nanosheets via energetic material deflagration. Nano Res, 2018, 11: 4735-4743

15 Liu Y, Huang B, Peng S, et al. Deflagration synthesis of nitrogen/ fluorine co-doped hollow carbon nanoparticles with excellent oxygen reduction performance. Inorg Chem Front, 2018, 5: 13071313

16 Dahan M, Komarala E, Fadeev L, et al. Methane dry reforming catalyst prepared by the co-deflagration of high-nitrogen energetic complexes. J Mater Chem A, 2019, 7: 141-149

17 Wang B, Feng Y, Qi X, et al. Designing explosive poly (ionic liquid)s as novel energetic polymers. Chem Eur J, 2018, 24: 15897-15902

18 Yuan J, Giordano C, Antonietti M. Ionic liquid monomers and polymers as precursors of highly conductive, mesoporous, graphitic carbon nanostructures. Chem Mater, 2010, 22: 5003-5012

19 Fellinger TP, Thomas A, Yuan J, et al. 25th anniversary article: "cooking carbon with salt": carbon materials and carbonaceous frameworks from ionic liquids and poly(ionic liquid)s. Adv Mater, 2013, 25: 5838-5855

20 Zhang S, Dokko K, Watanabe M. Carbon materialization of ionic liquids: from solvents to materials. Mater Horiz, 2015, 2: 168-197

21 Gong J, Antonietti M, Yuan J. Poly(ionic liquid)-derived carbon with site-specific $\mathrm{N}$-doping and biphasic heterojunction for enhanced $\mathrm{CO}_{2}$ capture and sensing. Angew Chem Int Ed, 2017, 56: 7557-7563

22 Gong J, Lin H, Antonietti M, et al. Nitrogen-doped porous carbon 
nanosheets derived from poly(ionic liquid)s: hierarchical pore structures for efficient $\mathrm{CO}_{2}$ capture and dye removal. J Mater Chem A, 2016, 4: 7313-7321

23 Zhang P, Yuan J, Fellinger TP, et al. Improving hydrothermal carbonization by using poly(ionic liquid)s. Angew Chem Int Ed, 2013, 52: 6028-6032

24 Balach J, Wu H, Polzer F, et al. Poly(ionic liquid)-derived nitrogendoped hollow carbon spheres: synthesis and loading with $\mathrm{Fe}_{2} \mathrm{O}_{3}$ for high-performance lithium ion batteries. RSC Adv, 2013, 3: 79797986

25 Zhao Q, Fellinger TP, Antonietti M, et al. Nitrogen-doped carbon capsules via poly(ionic liquid)-based layer-by-layer assembly. Macromol Rapid Commun, 2012, 33: 1149-1153

26 Shao M, Chang Q, Dodelet JP, et al. Recent advances in electrocatalysts for oxygen reduction reaction. Chem Rev, 2016, 116: 3594-3657

27 Wang T, Wang J, Wang X, et al. Graphene-templated synthesis of sandwich-like porous carbon nanosheets for efficient oxygen reduction reaction in both alkaline and acidic media. Sci China Mater, 2018, 61: 915-925

$28 \mathrm{Wu} \mathrm{ZY}, \mathrm{Xu} \mathrm{XX}, \mathrm{Hu} \mathrm{BC}$, et al. Iron carbide nanoparticles encapsulated in mesoporous $\mathrm{Fe}-\mathrm{N}$-doped carbon nanofibers for efficient electrocatalysis. Angew Chem Int Ed, 2015, 54: 8179-8183

29 Liang HW, Wu ZY, Chen LF, et al. Bacterial cellulose derived nitrogen-doped carbon nanofiber aerogel: an efficient metal-free oxygen reduction electrocatalyst for zinc-air battery. Nano Energy, 2015, 11: 366-376

30 Wu ZY, Xu SL, Yan QQ, et al. Transition metal-assisted carbonization of small organic molecules toward functional carbon materials. Sci Adv, 2018, 4: eaat0788

31 Chen YZ, Wang $\mathrm{C}, \mathrm{Wu} \mathrm{ZY}$, et al. From bimetallic metal-organic framework to porous carbon: high surface area and multicomponent active dopants for excellent electrocatalysis. Adv Mater, 2015, 27: 5010-5016

32 Feng T, Qin H, Zhang M. Co@C nanoparticle embedded hierarchically porous $\mathrm{N}$-doped hollow carbon for efficient oxygen reduction. Chem Eur J, 2018, 24: 10178-10185

33 Amiinu IS, Liu X, Pu Z, et al. From 3D ZIF nanocrystals to Co- $\mathrm{N}_{x} /$ $\mathrm{C}$ nanorod array electrocatalysts for ORR, OER, and Zn-air batteries. Adv Funct Mater, 2018, 28: 1704638

34 Li H, Zhang Z, Dou M, et al. Towards high-performance electrocatalysts for oxygen reduction: inducing atomic-level reconstruction of $\mathrm{Fe}-\mathrm{N}_{x}$ site for atomically dispersed $\mathrm{Fe} / \mathrm{N}$-doped hierarchically porous carbon. Chem Eur J, 2018, 24: 8848-8856

35 Yang L, Lv Y, Cao D. Co,N-codoped nanotube/graphene 1D/2D heterostructure for efficient oxygen reduction and hydrogen evolution reactions. J Mater Chem A, 2018, 6: 3926-3932

36 Liu M, Lin H, Mei Z, et al. Tuning cobalt and nitrogen Co-doped carbon to maximize catalytic sites on a superabsorbent resin for efficient oxygen reduction. ChemSusChem, 2018, 11: 3631-3639

37 Xiao X, Li Q, Yuan X, et al. Ultrathin nanobelts as an excellent bifunctional oxygen catalyst: insight into the subtle changes in structure and synergistic effects of bimetallic metal-organic framework. Small Methods, 2018, 2: 1800240
38 Li B, Shi Y, Huang K, et al. Cobalt-doped nickel phosphite for high performance of electrochemical energy storage. Small, 2018, 14: 1703811

39 Li X, Wei J, Li Q, et al. Nitrogen-doped cobalt oxide nanostructures derived from cobalt-alanine complexes for highperformance oxygen evolution reactions. Adv Funct Mater, 2018, 28: 1800886

40 Ma J, Xiang Z, Zhang J. Three-dimensional nitrogen and phosphorous Co-doped graphene aerogel electrocatalysts for efficient oxygen reduction reaction. Sci China Chem, 2018, 61: 592-597

41 Aijaz A, Masa J, Rösler C, et al. $\mathrm{Co@} \mathrm{Co}_{3} \mathrm{O}_{4}$ encapsulated in carbon nanotube-grafted nitrogen-doped carbon polyhedra as an advanced bifunctional oxygen electrode. Angew Chem Int Ed, 2016, 55: 4087-4091

Acknowledgements This work was financially supported by the National Natural Science Foundation of China (21703218 and 21875228), and Shenzhen Science and Technology Innovation Committee (JCYJ20151013162733704).

Author contributions Zhang Q and Zhang J proposed the research and guided the whole project. Wang B and Liu Y performed the main experiments and wrote the manuscript. Deng $M$, Luo J, Yang G and Zhang $S$ helped analyze the data. All authors contributed to the general discussion.

Conflict of interest The authors declare that they have no conflict of interest.

Supplementary information Supporting data are available in the online version of the paper.

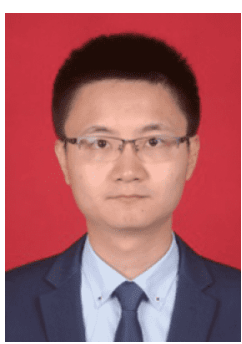

Binshen Wang completed his $\mathrm{PhD}$ in 2016 at East China Normal University. From 2016 to 2018, he worked as a postdoctoral fellow at the Institute of Chemical Materials (ICM), China Academy of Engineering Physics (CAEP). Now he is a postdoctoral fellow at Harbin Institute of Technology (Shenzhen). His research interest focuses on the synthesis of advanced energy materials.

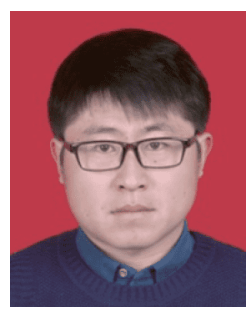

Yousong Liu received his $\mathrm{PhD}$ from Nanjing University of Aeronautics and Astronautics in 2015. From 2016 to 2018, he worked as a postdoctoral fellow at ICM, CAEP. Now he is an associate professor in ICM. His research interest focuses on the synthesis of doped carbon materials via energetic materials deflagration. 


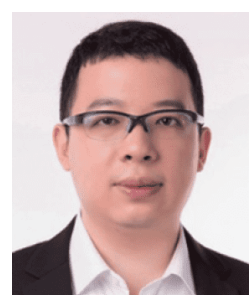

Jiaheng Zhang obtained his $\mathrm{PhD}$ from China Agricultural University in 2013. From 2012 to 2015, he was a visiting scholar at the University of Idaho, and subsequently, he was a postdoctoral fellow. He was awarded the prestigious Japan Society for Promotion of Science (JSPS) fellowship at Yokohama National University in 2015. In 2016, he started to carry out independent research at Harbin Institute of Technology (Shenzhen). His research interests include ionic liquid chemistry and energetic materials.

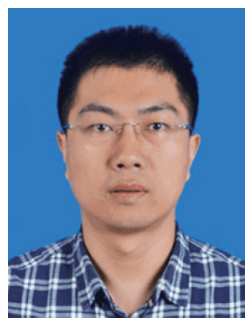

Qinghua Zhang received his $\mathrm{PhD}$ from Lanzhou Institute of Chemical Physics in 2008. From 2010 to 2012, he worked as a CNRS associate researcher at the University of Poitiers, France. From 2012 to 2013, he worked as a postdoctoral fellow at the University of Idaho, USA. Now he is a professor at the Institute of Chemical Materials, China Academy of Engineering Physics. His research interest focuses on the synthesis of new high-energy-density materials, polynitrogen compounds, and energetic ionic liquids.
含能五唑化钴衍生钴修饰氮掺杂碳材料的制备及 其催化氧还原反应性能研究

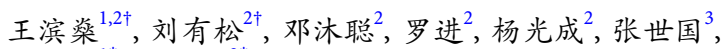
张嘉恒 ${ }^{1^{*}}$, 张庆华 $^{2^{*}}$

摘要 自首例含有五唑阴离子 $\left(\right.$ cyclo $\left.-\mathrm{N}_{5}{ }^{-}\right)$的稳定固态聚氮化合物被 报道以来，探索新兴五唑化合物的制备与应用吸引着科学家们的 极大兴趣. 本文发展了一种以五唑化钴与含能聚离子液体为前驱 体, 利用独特的爆燃反应制备钴修饰氮掺杂碳材料的新方法. 凭借 前驱体的含能特性, 所得材料具有典型的核-壳纳米结构, 氮掺杂碳 层包裹的钴纳米颗粒分布均匀. 材料 $5 \% \mathrm{Co}\left(\mathrm{N}_{5}\right)_{2}$-EPIL- 900 在氧还原 反应中展现出优异的电催化性能、稳定性和抗甲醇毒化能力. 本 工作为以含能五唑化合物为前驱体高效制备功能碳材料提供了新 途径. 